\title{
Role of combined indacaterol and glycopyrronium bromide (QVAI49) for the treatment of COPD in Japan
}

\section{Nobuyuki Horita \\ Takeshi Kaneko}

Department of Pulmonology, Yokohama City University Graduate School of Medicine, Yokohama, Japan
This article was published in the following Dove Press journal: International Journal of COPD

2I April 2015

Number of times this article has been viewed
Correspondence: Nobuyuki Horita Department of Pulmonology, Yokohama City University Graduate School of Medicine, 3-9 Fukuura, Kanazawa-ku, Yokohama 236-0004, Japan

Tel +8I 457872630

Fax +8I 457863444

Email nobuyuki_horita@yahoo.co.jp
Abstract: Once-daily dual-bronchodilator therapy with combined indacaterol and glycopyrronium bromide in one device (Ultibro, Breezhaler), often called QVA149, was first approved in 2013 in Japan and Europe. As of November 2014, more than 40 countries had approved this medication except for the USA. This is the first dual bronchodilator in one device. Now, the Breezhaler is the only device that can provide long-acting muscarinic antagonist (glycopyrronium bromide), longacting beta agonist (indacaterol), and a combination of the two medications (QVA149). The choice among the three medications allows a patient to use the same inhalation device even when the regimen is changed from single-bronchodilator therapy to dual-bronchodilator therapy. In addition, the quick bronchodilation effect and once-daily administration can improve patient adherence to medical treatment for chronic obstructive pulmonary disease (COPD). To our knowledge, as of November 2014, the safety and the efficacy of QVA149 have been evaluated in 14 randomized controlled trials. The 14 trials generally showed good safety profiles, and there were better or not-inferior bronchodilator effects of QVA149 when compared with placebo, or other inhaled medication. According to the Japanese Respiratory Society guidelines, QVA149 is a combination of the two first-line bronchodilators. Our meta-analysis indicated that QVA149 is superior to the salmeterol-fluticasone combination to treat COPD in respect of the frequency of adverse effects, exacerbation, pneumonia, and improvement of trough forced expiratory volume in 1 second $\left(\mathrm{FEV}_{1}\right)$. Thus, we believe that QVA149 can be a key medication for COPD treatments.

Keywords: bronchodilator agents, dry powder inhalers, delivery of health care, guideline, meta-analysis, muscarinic antagonists

\section{Introduction}

Chronic obstructive pulmonary disease (COPD) is a progressive inflammatory disease characterized by airflow limitation, in which inhaled bronchodilators play an essential part in disease control. ${ }^{1}$ Both long-acting muscarinic antagonists (LAMA) and long-acting beta agonists (LABA) are currently regarded as the key medications for patients with COPD. ${ }^{1}$

Among inhaled bronchodilators, recently-introduced indacaterol (Onbrez) and glycopyrronium bromide (Seebri) are the preferred choices for COPD treatment because of their powerful bronchodilator effects and a simple once-daily inhalation regimen. ${ }^{2}$ Indacaterol is the first once-daily LABA for treatment of COPD, and is administered by the Breezhaler inhalation device. ${ }^{3-5}$ This agent has been called ultra-LABA because it provides both the quick bronchodilation effect similar to short-acting beta agonists, and a 24-hour bronchodilation effect permitting the once-daily administration. The quick bronchodilation effect and once-daily administration can improve patient adherence to medical treatment for COPD. ${ }^{6}$ Currently, the recommended dose for 
indacaterol differs among countries: 150-300 $\mu \mathrm{g} / \mathrm{d}$ in Europe, $150 \mu \mathrm{g} / \mathrm{d}$ in Japan, and $75 \mu \mathrm{g} / \mathrm{d}$ in the USA. ${ }^{7}$ Glycopyrronium bromide is the second once-daily inhaled LAMA after tiotropium bromide (Spiriva). With a daily dose of $50 \mu \mathrm{g}$ via the Breezhaler, glycopyrronium bromide can provide 24-hour bronchodilation with a rapid onset of action, faster than that of tiotropium. Similar to indacaterol, glycopyrronium bromide also has advantages for patient adherence thanks to its quick and long-lasting bronchodilating effect. The safety profile of glycopyrronium bromide is also similar to that of tiotropium in terms of the incidence of adverse events and muscarinic side effects. ${ }^{8-10}$ Indacaterol and glycopyrronium bromide were firstly approved in Japan in July 2011 and September 2012, respectively, and are now approved in many other countries.

Even though LAMA and LABA have excellent therapeutic profiles, a bronchodilator monotherapy is not always satisfactory for patients with advanced COPD. In that situation, a dual-bronchodilator therapy consisting of LAMA and LABA is believed to be a good option. ${ }^{1}$ Given the rationale above, coadministration of indacaterol and glycopyrronium bromide seems promising to treat advanced COPD. ${ }^{2}$ In addition to the pharmacological profile, this coadministration permits a patient to use the same Breezhaler device and requires a patient to learn only one inhalation procedure.

Once-daily dual-bronchodilator therapy with combined indacaterol and glycopyrronium bromide in one device (Ultibro), often called QVA149, was first approved in 2013 in Japan and Europe. ${ }^{11-13}$ As of November 2014, more than 40 countries had approved this medication worldwide, though the USA has not approved it. This is the first dual bronchodilator in one device followed by combined umeclidinium and vilanterol (Anoro) inhaled via the Ellipta device. ${ }^{14}$ Now, the Breezhaler is the only device that can provide three types of inhaled medication, LAMA, LABA, and combined LAMA + LABA. The choice among the three medications allows a patient to use the same inhalation device even when the regimen is changed from single-bronchodilator therapy to dual-bronchodilator therapy. This user-friendliness is similar to that provided by the Diskus inhaler device and the Turbuhaler inhaler device, which can provide inhaled corticosteroids (ICS), LABA, and combined ICS + LABA in the same device for asthma. ${ }^{15,16}$ Compared with the commonly used indacaterol dose of $150 \mu \mathrm{g}$ for a single bronchodilator, QVA149 has a lower indacaterol dose of $110 \mu \mathrm{g}$. This is because combined medication can provide better delivery to the lung.
Historically, the Japanese government had approved newly-developed medications after a long time lag of about 2 years since the medication has been approved in many other countries. ${ }^{17,18}$ Various explanations have been provided for this. The government weighed checking the safety profile of the new medication in other countries against the merit of delivering the new medication sooner. Medical doctors in Japan hesitated to participate in the bothersome clinical trial partly because it rarely counted toward their promotion. Patients living in Japan generally hesitate to participate in clinical trials. Anyway, indacaterol, glycopyrronium bromide, and the combined medication made from them, were first approved in Japan, which was an epoch-making event for the Japanese health service.

In this review article, we first review the major randomized controlled trials (RCTs) that evaluated QVA149. Then, we discuss how to choose inhaled medication by comparing the Global Initiative for Chronic Obstructive Lung Disease (GOLD) document and the fourth edition of the COPD guidelines of the Japanese Respiratory Society (JRS). We hope this provides useful information for readers even in other countries. The manuscript was written in November 2014. Readers may be able to access updated data on the recent trials after the publication of the current article.

\section{Clinical trials}

To our knowledge, the safety and efficacy of QVA149 have been evaluated in 14 RCTs, all of which were sponsored by Novartis Pharma. ${ }^{19-32}$ Of these 14, one was a Phase II study, 13 were Phase III studies, 14 used a standard QVA149 dose, two used nonstandard high QVA149 doses, 11 were part of the IGNITE clinical trial program, nine have already been published, and two have been reported at conferences but have not been published (Table 1). ${ }^{19-32}$ Most studies compared QVA149 with indacaterol, glycopyrronium bromide, a combination of them, placebo, tiotropium, and salmeterol-fluticasone combination (SFC). According to already published articles, indacaterol, glycopyrronium, a combination of them, placebo, and SFC were always blinded, while tiotropium was often open labeled. Although QVA149 and tiotropium were directly compared in some trials, these comparisons were not evaluated as primary endpoints in most of the studies. The 14 RCTs generally showed good safety profiles, and there were better or not-inferior bronchodilator effects of QVA149 when compared with placebo, or other inhaled medication. Researchers and clinicians are probably most interested in the following two comparisons: QVA149 versus other coadministration of LAMA + LABA, and QVA149 versus 


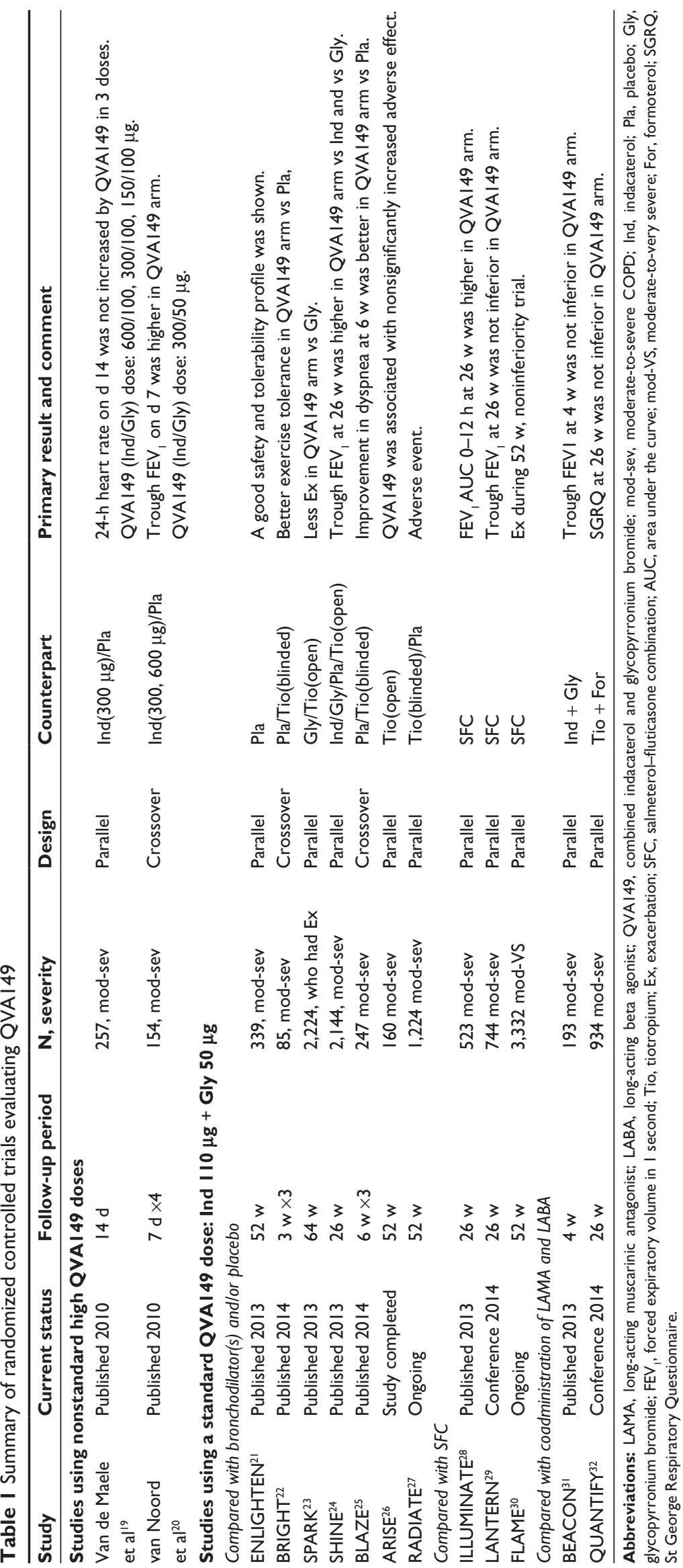


SFC. Two noninferior trials suggested that QVA149 was not inferior to coadministration of LAMA + LABA as regards trough forced expiratory volume in 1 second $\left(\mathrm{FEV}_{1}\right)$ and the St George Respiratory Questionnaire (SGRQ). However, it is not clear whether QVA149 is superior to coadministration of LAMA + LABA. Concerning QVA149 versus SFC, we performed a meta-analysis in the latter section. No study has ever conducted a head-to-head comparison between QVA149 and combined umeclidinium and vilanterol.

\section{Early studies using nonstandard high QVAI49 doses}

Before the currently approved dose of QVA149 of indacaterol $110 \mu \mathrm{g}+$ glycopyrronium $50 \mu \mathrm{g}$ was determined, some different QVA149 doses were used in two RCTs reported in 2010.

Van de Maele et $\mathrm{al}^{19}$ reported a result from a randomized, double-blind, placebo-controlled, parallel-group study including 257 moderate-to-severe COPD patients. This only Phase II study adopted five arms: QVA149 in doses of indacaterol $600 \mu \mathrm{g}+$ glycopyrronium $100 \mu \mathrm{g}$, indacaterol $300 \mu \mathrm{g}+$ glycopyrronium $100 \mu \mathrm{g}$, indacaterol $150 \mu \mathrm{g}+$ glycopyrronium $100 \mu \mathrm{g}$, indacaterol $300 \mu \mathrm{g}$, and placebo. The primary endpoint was change in 24-hour mean heart rate from baseline versus placebo on day 14 . There were no clinically significant differences in the 24-hour heart rate on day 14 among the three doses of QVA149, placebo, and indacaterol. No clinically relevant difference in side effects was observed. ${ }^{19}$

In the same month, van Noord et $\mathrm{al}^{20}$ reported a result from a randomized double-blind, placebo-controlled, fourperiod crossover trial assessing the efficacy and safety of QVA149. This study, with four treatment consequence arms consisting of QVA149 in a dose of indacaterol $300 \mu \mathrm{g}+$ glycopyrronium $50 \mu \mathrm{g}$, indacaterol $300 \mu \mathrm{g}$, indacaterol 600 $\mu \mathrm{g}$, and placebo, was the first study mainly designed to assess the bronchodilatory effect of QVA149. Trough FEV ${ }_{1}$ on day 7 was higher in the QVA149 arm than the indacaterol 300 $\mu \mathrm{g}$, indacaterol $600 \mu \mathrm{g}$, and placebo arms. ${ }^{20}$

\section{Studies using a standard dose since 2013}

Twelve RCTs were conducted using a standard QVA149 dose of indacaterol $110 \mu \mathrm{g}+$ glycopyrronium $50 \mu \mathrm{g}$. These included one non-IGNITE study, QUANTIFY, and 11 RCTs belonging to the IGNITE program.

\section{Comparison with bronchodilator(s) and/or placebo}

ENLIGHTEN was a 52-week, multicenter, double-blind, parallel-group, placebo-controlled trial to primarily evaluate
QVA149 concerning the safety and tolerability for treatmentemergent adverse events. ${ }^{21}$ Of 339 moderate-to-severe COPD patients, 226 and 113 were assigned to the QVA149 arm and to the placebo arm, respectively, with the medications delivered via the Breezhaler inhaler. QVA149 was well tolerated over the 52 weeks of treatment, with the overall incidence of adverse events and discontinuation being similar between the two arms. This study secondarily showed that, compared with placebo, QVA149 could provide better improvement in a 60-minute postdose $\mathrm{FEV}_{1}$ by $300 \mathrm{~mL} .^{21}$

BRIGHT was a randomized three-period crossover trial using QVA149, placebo, and blinded tiotropium arms. ${ }^{22}$ However, tiotropium was not evaluated for the primary endpoint but only for a sensitivity analysis. QVA149 significantly improved exercise endurance time at day 21 compared with placebo, but it did not improved exercise endurance time at day 21 compared with tiotropium. ${ }^{22}$

SPARK was a very-large-scale parallel-group RCT including 2,224 patients with severe or very severe COPD who had experienced at least one exacerbation in the previous 12 months requiring treatment with systemic corticosteroids or antibiotics. ${ }^{23}$ The patients were randomized to one of three arms: QVA149, glycopyrronium bromide, or open-label tiotropium. The primary objective was to investigate the superiority of QVA149 over glycopyrronium bromide for reducing of moderate-to-severe COPD exacerbation during 64 weeks. QVA149 marginally reduced moderate or severe exacerbation with a risk ratio of 0.88 (95\% confidence interval (CI): 0.77-0.99) compared with glycopyrronium bromide, but did not reach statistical significance when compared with tiotropium with a risk ratio of 0.90 (95\% CI: 0.79-1.02). ${ }^{23}$

SHINE was a very-large-scale 26-week RCT allocating 2,144 patients into five arms: QVA149, indacaterol, glycopyrronium, placebo, or open-label tiotropium. ${ }^{24}$ The primary endpoint was trough $\mathrm{FEV}_{1}$ at week 26 for QVA149 versus indacaterol and versus glycopyrronium. The trough $\mathrm{FEV}_{1}$ at week 26 was significantly improved in the QVA149 arm compared with both the indacaterol and glycopyrronium arms, with treatment differences of 0.07 and $0.09 \mathrm{~L}$, respectively. QVA149 also provided a significantly higher improvement in trough $\mathrm{FEV}_{1}$ compared with tiotropium at 26 weeks. $^{24}$

BLAZE was a multicenter, blinded, double-dummy, threeperiod crossover study that randomized 247 patients to one of the treatment consequence arms consisting of the following: QVA149, placebo, or blinded tiotropium. ${ }^{25}$ The Transition Dyspnea Index total score at 6 weeks was improved in the QVA149 arm compared with placebo (primary endpoint) and compared with tiotropium (secondary endpoint). ${ }^{25}$ 
ARISE was a nonblinded parallel-group RCT to assess the efficacy and safety profile of the medication, which randomly assigned 121 and 39 subjects to the QVA149 and tiotropium arms, respectively. ${ }^{26}$ As expected, QVA149

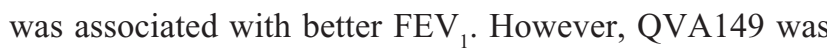
associated with a tendency to cause more severe adverse events (16\% [19/119] in the QVA149 arm, 5.1\% [2/39] in the tiotropium arm; $P$ for Fisher's exact test $>0.05$ ) and more adverse events requiring medication withdrawal (9.2\% [11/119] in QVA149 arm, 0\% [0/39] in the tiotropium arm; $P$ for Fisher's exact test $>0.05$ ). This large difference concerning adverse events was not observed in other RCTs. Novartis Pharma explained that the observed difference of adverse effect rates in the two arms was due to the difference that remained after randomization..$^{33}$ We hope that the ongoing large-scale RADIATE trial focusing on overall serious adverse events will remove the concerns about the safety profile. ${ }^{27}$

RADIATE is a double blind, parallel-group RCT with 1,224 COPD patients to evaluate the overall serious adverse event rate over 52 weeks. ${ }^{27}$ This consists of QVA149, tiotropium, and placebo arms. The estimated study completion date is January $2015 .{ }^{27}$

\section{Comparison with SFC}

SFC is one of the most widely prescribed combined inhaled medications for COPD. While SFC was approved for a middle $(500 \mu \mathrm{g} / \mathrm{d})$ dose of fluticasone in Japan and the USA, SFC was also approved with a high $(1,000 \mu \mathrm{g} / \mathrm{d})$ dose of fluticasone in the EU. We will review three trials that used SFC with a high dose of fluticasone.

ILLUMINATE was a multicenter double-blind, doubledummy, parallel-group RCT with 523 moderate-to-severe COPD patients. ${ }^{28}$ This study revealed, as a primary endpoint, that at 26 weeks, the $\mathrm{FEV}_{1}$ area under the curve $(0-12 \mathrm{~h})$ was significantly higher with QVA149 than with SFC. The study also showed that the overall incidence of adverse events and the incidence of serious adverse events were not different between the two arms. ${ }^{28}$

LANTERN is a double-blind, double-dummy, parallelgroup RCT with 744 patients with moderate-to-severe COPD to evaluate the noninferiority of QVA149 to SFC for postdose trough $\mathrm{FEV}_{1}$ at 26 weeks. ${ }^{29}$ In addition to noninferiority, QVA149 demonstrated significant superiority over SFC for trough $\mathrm{FEV}_{1}$. This result has not been published as of November 2014. ${ }^{29}$

FLAME included the largest accrual of patients of 3,332 among 11 trials under the IGNITE program..$^{30}$ This double-blind, parallel-group RCT is still ongoing, and the estimated study completion date is September 2015. This study will report the rate of COPD exacerbation over 52 weeks of treatment. ${ }^{30}$

\section{Comparison with coadministration of LAMA + LABA}

BEACON was a multicenter, double-blind, parallel-group RCT with 193 patients with moderate-to-severe COPD. ${ }^{31}$ This study directly compares QVA149 in a dose of indacaterol $110 \mu \mathrm{g}+$ glycopyrronium $50 \mu \mathrm{g}$ with coadministration of glycopyrronium bromide $150 \mu \mathrm{g}+$ indacaterol $50 \mu \mathrm{g}$. The primary endpoint was to evaluate the noninferiority of QVA149 for trough $\mathrm{FEV}_{1}$ after 4 weeks of treatment. It was $1.46 \pm 0.02 \mathrm{~L}$ for QVA149 and $1.46 \pm 0.18 \mathrm{~L}$ for the coadministration, which showed no significant difference. Both groups showed similar $\mathrm{FEV}_{1}$ area under the curve $0-4$ hour at day 1 and week 4 , reduction in symptom score, use of rescue medication within 4 weeks, and rate of adverse events. ${ }^{31}$

QUANTIFY was a double-blind, double-dummy RCT to compare QVA149 and coadministration of tiotropium and formoterol. ${ }^{32}$ The combination of tiotropium and formoterol is the desirable counterpart because of its repeatedly proved efficacy and safety. Of special significance is that tiotropium is a medication that was regarded as the only first-line medication to treat COPD for a decade. ${ }^{1,34}$ The primary objective was to confirm noninferiority in quality of life evaluated with SGRQ for COPD patients at 26 weeks, and this objective was achieved. Secondary endpoints additionally revealed some novel findings. The percentage of patients achieving $\geq 1$ point improvement in the Transition Dyspnea Index was higher with the QVA149 arm (49.6\%) than with the tiotropium and formoterol arms (42.4\%, $P=0.033)$. Even though it did not reach statistical significance, QVA149 was associated with favorable results concerning SGRQ for COPD patients, Transition Dyspnea Index, and rate of moderate/severe exacerbations. The incidence of adverse events was comparable between the two treatment arms. ${ }^{32,35}$

\section{Choice of the combined inhaled medication: bronchodilators or ICS}

According to the GOLD guidelines and the JRS fourth edition of the COPD guidelines, LAMA, LABA, and ICS, which are administered via an inhaler device, are key medications for COPD treatment. ${ }^{1,36}$ However, recommendations for bronchodilators and ICS are different between the two guidelines. The GOLD guidelines recommend ICS as the first-line medication for a patient with Groups C and D COPD: severe-to-very 


\section{Clinical presentation}

Aged/Smoker

(Cough, sputum, asymptomatic)

$\downarrow$

Dyspnea only on hard exertion

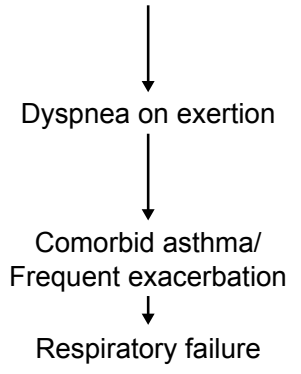

Pharmacological treatment

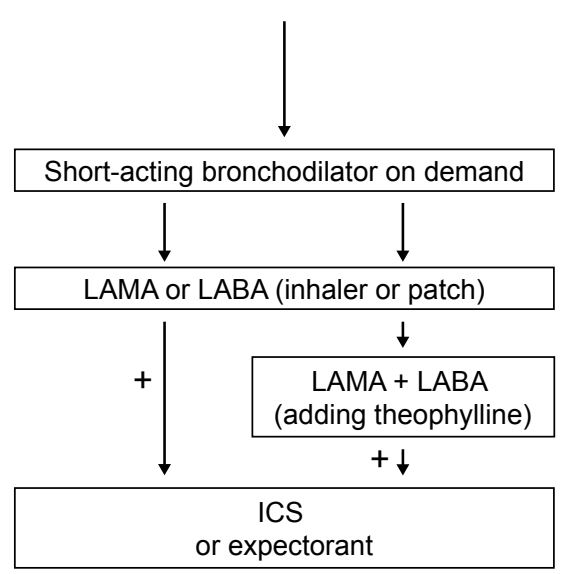

$\underline{\text { Nonpharmacological treatment }}$

$\downarrow$

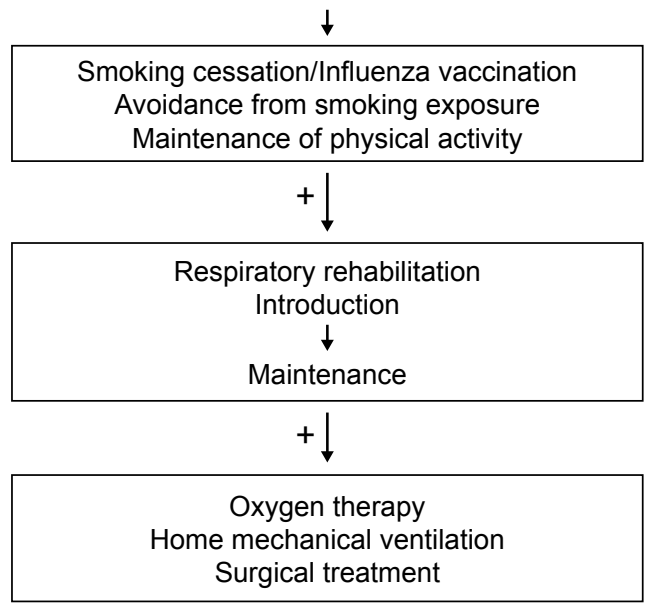

Figure I Algorithm recommended by the fourth edition of Japanese Respiratory Society COPD guidelines.

Notes: Copyright @ 2013 The Japanese Respiratory Society. Adapted from Fourth Edition of the Japanese Respiratory Society COPD Guideline for Diagnosis and Treatment. Tokyo, Japan: The Japanese Respiratory Society; 2013. Japanese. ${ }^{36}$

Abbreviations: LAMA, long-acting muscarinic antagonist; LABA, long-acting beta agonist; ICS, inhaled corticosteroids; COPD, chronic obstructive pulmonary disease.

severe airflow limitation, $\geq 2$ exacerbations per year, and/or $\geq 1$ with hospitalization for exacerbation. ${ }^{1}$ On the other hand, JRS guidelines lay less emphasis on the use of ICS. Two figures are illustrated in the JRS guidelines. ${ }^{36}$ The first one is an algorithm (Figure 1). This algorithm generally recommends LAMA + LABA prior to ICS. The other is a stepwise approach, which permits prescribing ICS only after LAMA and LABA have been prescribed (Figure 2).

The most important favorable effect of ICS for COPD is to decrease the rate of exacerbation. ${ }^{1,37}$ Nonetheless, since the beginning, COPD patients in Japan have had fewer exacerbations than those in other countries; $;{ }^{38}$ thus, Japanese

Respiratory rehabilitation

Smoking cessation, vaccination, diagnosis, and control for comorbidity

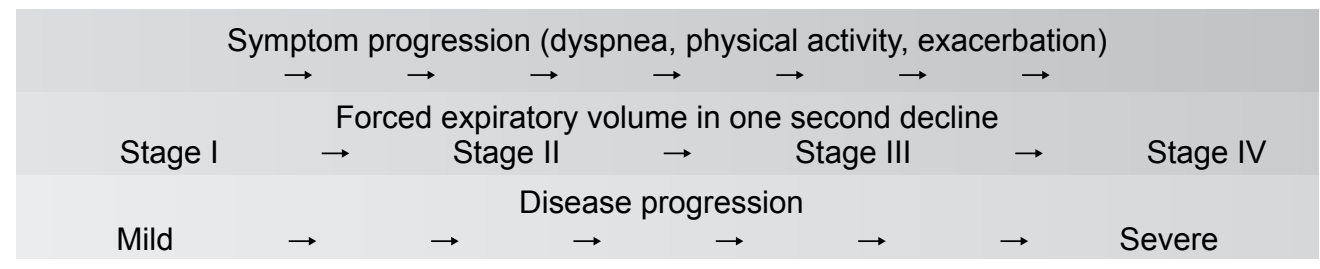

Figure 2 Stepwise approach recommended by the fourth edition of Japanese Respiratory Society COPD guidelines.

Notes: Copyright (C2013 The Japanese Respiratory Society. Adapted from Fourth Edition of the Japanese Respiratory Society COPD Guideline for Diagnosis and Treatment. Tokyo, Japan: The Japanese Respiratory Society; 2013 . Japanese. ${ }^{36}$ Arrows indicate disease progression.

Abbreviations: LAMA, long-acting muscarinic antagonist; LABA, long-acting beta agonist; ICS, inhaled corticosteroids; COPD, chronic obstructive pulmonary disease. 
patients have a lesser chance of benefitting from a decreasing rate of exacerbation. This may partly explain why the JRS guidelines suggested the ICS only after dual-bronchodilator therapy (Figures 1 and 2). ${ }^{36} \mathrm{COPD}$ and bronchial asthma are two typical respiratory diseases presenting obstructive airway disorder, and it is often difficult to tell them apart. ${ }^{39}$ If a physician cannot confidently differentiate COPD and asthma, one attractive treatment option is covering both COPD and asthma by prescribing bronchodilators and ICS.
Thanks to the very high prevalence of CT scans, ${ }^{40}$ physicians in Japan have the advantage of differentiating emphysema and bronchial asthma. Therefore, to treat confidently diagnosed emphysema cases in Japan, a physician usually need not cover bronchial asthma using ICS. This factor also resulted in a low ICS prescription rate in Japan. ${ }^{41,42}$ As shown in the Clinical Trial section, QVA149 provides safe, quick, and long-lasting bronchodilation. In addition, the Breezhaler is the only device that can provide LAMA,

\section{Trough forced expiratory volume in one second}

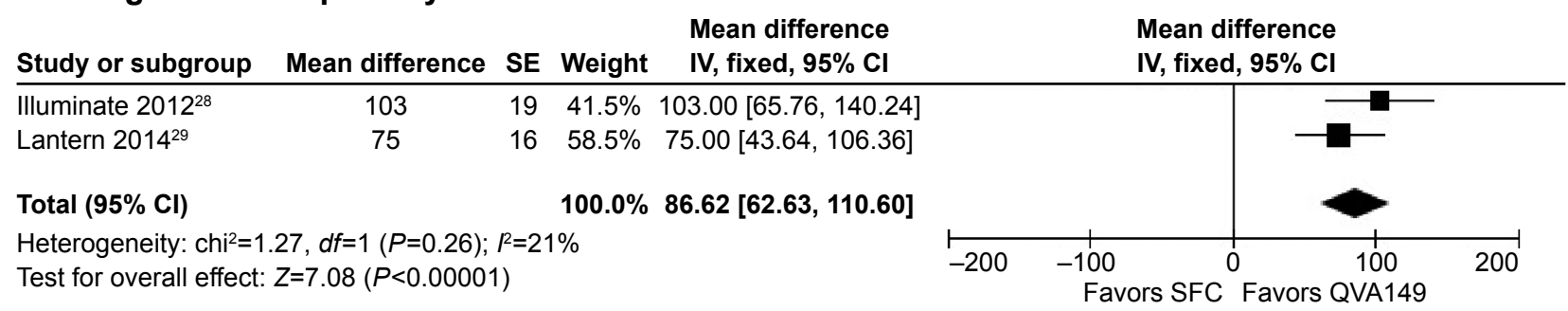

\section{Any adverse event}

QVA149 SFC Odds ratio

Study or subgroup Events Total Events Total Weight $\mathrm{M}-\mathrm{H}$, fixed, $95 \% \mathrm{Cl} \quad \mathrm{M}-\mathrm{H}, \mathrm{fixed}, \mathbf{9 5 \%} \mathrm{Cl}$

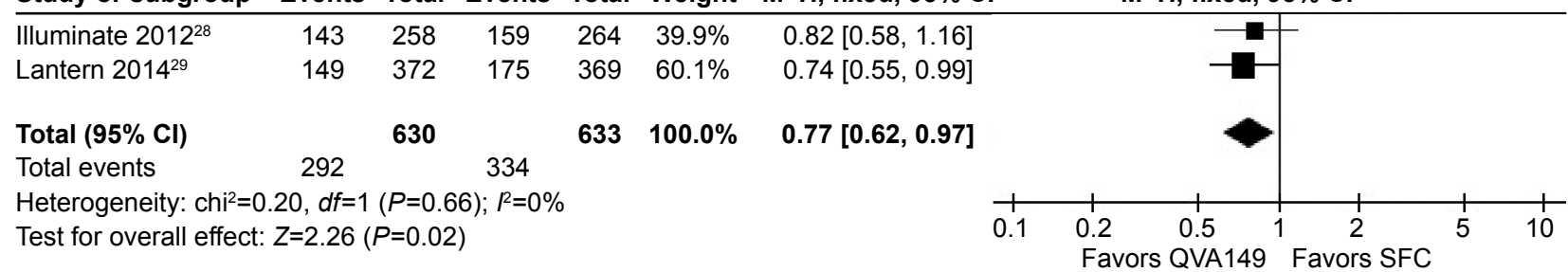

\section{Exacerbation}

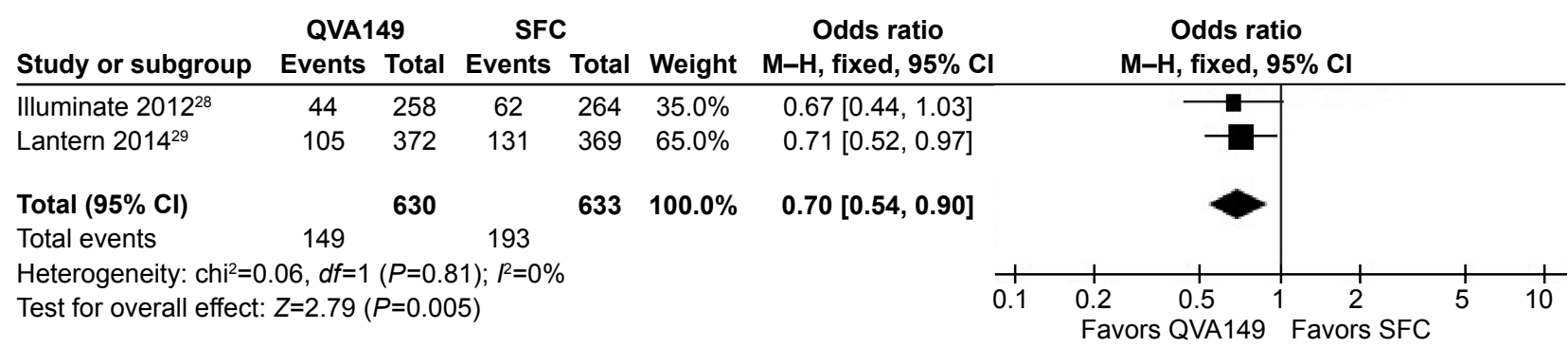

\section{Pneumonia}

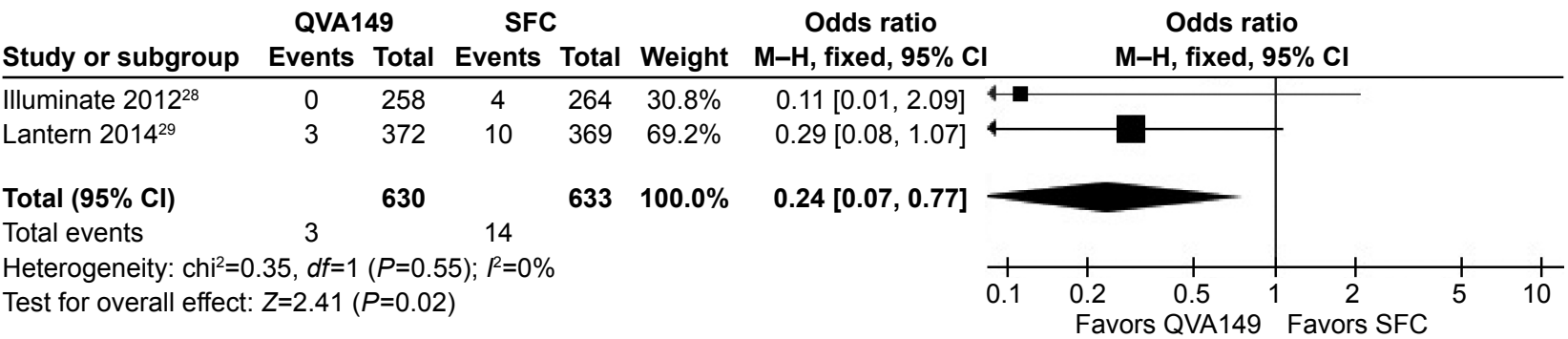

Figure 3 Meta-analysis to compare QVAI49 and SFC.

Abbreviations: QVAI49, combined indacaterol and glycopyrronium bromide; SE, standard error; IV, inverse variance; Cl, confidence interval; SFC, salmeterol-fluticasone combination; M-H, Mantel-Haenszel. 
LABA, and combined LAMA + LABA. Given these advantages of QVA149 and the JRS guidelines that preferred bronchodilators over ICS, QVA149 can play a central role in COPD treatments in Japan.

We understand that ICS has been more frequently prescribed in other countries. A high utilization rate of ICS in the last decade was revealed in some RCTs: ${ }^{43} 48 \%$ in Toward a Revolution in COPD Health, ${ }^{44} 77 \%$ in The Canadian Optimal Therapy of COPD Trial, ${ }^{45} 50 \%$ in Investigating New Standards for Prophylaxis in Reducing Exacerbations, ${ }^{46}$ and $61 \%$ in Understanding Potential Long-term Impacts on Function with Tiotropium. ${ }^{34}$ Similarly, a market research study estimated that ICS were used by $>70 \%$ of patients with COPD in the USA and EU. ${ }^{43}$ Some felt that the current prescription rate of ICS for COPD patients is more than necessary. ${ }^{43,47}$

We performed a meta-analysis from the data of ILLUMINATE and LANTERN, which directly compared QVA149 and SFC (Figure 3). ${ }^{28,29}$ This shows that COPD patients treated by QVA149 had larger trough $\mathrm{FEV}_{1}$ by $86 \mathrm{~mL}(95 \%$ CI: $62-111 \mathrm{~mL} . I^{2}=21 \%$ ), less adverse events with an odds ratio of 0.77 ( $95 \% \mathrm{CI}$ : $0.62-0.97 . I^{2}=0 \%$ ), less exacerbation with an odds ratio of 0.70 (95\% CI: $\left.0.54-0.90 . I^{2}=0 \%\right)$, and less pneumonia with an odds ratio of 0.24 (95\% CI: $\left.0.07-0.77 . I^{2}=0 \%\right)$. GOLD guidelines recommend LAMA + ICS or LABA + ICS as the first-choice treatment for Groups $\mathrm{C}$ and $\mathrm{D}$ cases, ie, exacerbation high-risk cases. ${ }^{1}$ This recommendation is based mainly on the observation that fluticasone propionate decreased exacerbation. ${ }^{1,37}$ However, our meta-analysis indicated that QVA149 was related to less exacerbation than SFC. We believe QVA149 is a better option for COPD treatment even after considering the rate of exacerbation.

\section{Health care system in Japan}

The Japanese government provides universal health coverage, which allows all residents in Japan to access preventive and curative services at an affordable cost. ${ }^{48}$ Patients have the right to choose any physicians or facilities they wish, without any restriction by insurance systems. Medical fees are strictly regulated by the government all over the country. Depending on the patient's age and family income, a patient is responsible for paying $0 \%-30 \%$ of total medical fees, and the government pays the remaining cost. ${ }^{48}$ Japanese residents like to visit hospitals for relatively minor problems and often seek very intensive examination and treatment. Most patients are very satisfied with this lowcost free-access medical system. This medical system also indirectly makes a clinical trial in Japan difficult. Although, in many countries, participating in a clinical trial provides a good chance for free access to the latest medical care for a patient who does not have medical insurance, a patient in Japan need not seek free medical care as all Japanese citizens already have the right to low-cost or nearly-free medical care. ${ }^{48-51}$ Now, Japan is the world's fastest aging society, and Japanese have the longest life expectancy in the world. However, Japan spent only $8.5 \%$ of the nation's gross domestic product, or US $\$ 2,873$ per capita, on health. This amount was less than the average of $9.6 \%$ across the Organization for Economic Co-operation and Development countries, and about half as much as that in the United States. The Japanese health care system can be a good example for other countries.

\section{Conclusion}

QVA149 is a powerful, quick, long-acting combined bronchodilator with a good safety profile. According to the JRS guidelines, QVA149 is a combination of the two first-line bronchodilators (Figures 1 and 2). ${ }^{42}$ It is a great advantage of the Breezhaler device covering the two first-line medications, LAMA and LABA, and a combination of the two medications. Furthermore, our meta-analysis indicated that QVA149 is superior to SFC in treating COPD as regards frequency of adverse effects, exacerbation, pneumonia, and improvement of trough $\mathrm{FEV}_{1}$. Thus, we believe that QVA149 can be a key medication for COPD treatment.

\section{Financial statement}

No support in the form of grants, gifts, equipment, and/or drugs was provided for the current study.

\section{Disclosure}

Kaneko T received grants and/or lecture fees from GlaxoSmithKline, Astellas, AstraZeneca, Boehringer Ingelheim, and Novartis within the last 3 years. The authors report no other conflicts of interest in this work.

\section{References}

1. Global Initiative for Chronic Obstructive Lung Disease. Global strategy for the diagnosis, management, and prevention of COPD, 2014. Available from: http://www.goldcopd.org/. Accessed October 20, 2014.

2. Vincken W, Aumann J, Chen H, Henley M, McBryan D, Goyal P. Efficacy and safety of coadministration of once-daily indacaterol and glycopyrronium versus indacaterol alone in COPD patients: the GLOW6 study. Int J Chron Obstruct Pulmon Dis. 2014;9:215-228.

3. Chung VC, Ma PH, Hui DS, Tam WW, Tang JL. Indacaterol for chronic obstructive pulmonary disease: systematic review and meta-analysis. PLoS One. 2013;8:e70784. 
4. Donohue JF, Fogarty C, Lötvall J, et al; INHANCE Study Investigators. Once-daily bronchodilators for chronic obstructive pulmonary disease: indacaterol versus tiotropium. Am J Respir Crit Care Med. 2010;182: $155-162$

5. D’Urzo A, Ferguson GT, van Noord JA, et al. Efficacy and safety of once-daily NVA237 in patients with moderate-to-severe COPD: the GLOW1 trial. Respir Res. 2011;12:156.

6. Rossi A, Polese G. Indacaterol: a comprehensive review. Int J Chron Obstruct Pulmon Dis. 2013;8:353-363.

7. Steiropoulos P, Archontogeorgis K, Nena E, Bouros D. New developments in the management of COPD: clinical utility of indacaterol $75 \mu \mathrm{g}$. Int J Chron Obstruct Pulmon Dis. 2014;9:1-7.

8. Chapman KR, Beeh KM, Beier J, et al. A blinded evaluation of the efficacy and safety of glycopyrronium, a once-daily long-acting muscarinic antagonist, versus tiotropium, in patients with COPD: the GLOW5 study. BMC Pulm Med. 2014;14:4.

9. Buhl R, Banerji D. Profile of glycopyrronium for once-daily treatment of moderate-to-severe COPD. Int J Chron Obstruct Pulmon Dis. 2012;7:729-741.

10. Ulrik CS. Once-daily glycopyrronium bromide, a long-acting muscarinic antagonist, for chronic obstructive pulmonary disease: a systematic review of clinical benefit. Int J Chron Obstruct Pulmon Dis. 2012;7:673-678.

11. Compton C, McBryan D, Bucchioni E, Patalano F. The Novartis view on emerging drugs and novel targets for the treatment of chronic obstructive pulmonary disease. Pulm Pharmacol Ther. 2013;26:562-573.

12. Frampton JE. QVA149 (indacaterol/glycopyrronium fixed-dose combination): a review of its use in patients with chronic obstructive pulmonary disease. Drugs. 2014;74:465-488.

13. Schachter EN. Indacaterol/glycopyrronium bromide fixed-dose combination for the treatment of COPD. Drugs Today (Barc). 2013;49: 437-446.

14. Scott LJ, Hair P. Umeclidinium/Vilanterol: first global approval. Drugs. 2014;74:389-395.

15. Nelson HS. Advair: combination treatment with fluticasone propionate/ salmeterol in the treatment of asthma. J Allergy Clin Immunol. 2001; 107:398-416.

16. Kuna P, Kuprys I. Symbicort Turbuhaler: a new concept in asthma management. Int J Clin Pract. 2002;56:797-803.

17. Honig PK. Recent trends and success factors in reducing the lag time to approval of new drugs in Japan. Clin Pharmacol Ther. 2014; 95:467-469.

18. Ueno T, Asahina Y, Tanaka A, Yamada H, Nakamura M, Uyama Y. Significant differences in drug lag in clinical development among various strategies used for regulatory submissions in Japan. Clin Pharmacol Ther. 2014;95:533-541.

19. Van de Maele B, Fabbri LM, Martin C, Horton R, Dolker M, Overend T. Cardiovascular safety of QVA149, a combination of Indacaterol and NVA237, in COPD patients. COPD. 2010;7(6):418-427.

20. van Noord JA, Buhl R, Laforce C, et al. QVA149 demonstrates superior bronchodilation compared with indacaterol or placebo in patients with chronic obstructive pulmonary disease. Thorax. 2010;65: 1086-1091.

21. Dahl R, Chapman KR, Rudolf M, et al. Safety and efficacy of dual bronchodilation with QVA149 in COPD patients: the ENLIGHTEN study. Respir Med. 2013;107:1558-1567.

22. Beeh KM, Korn S, Beier J, et al. Effect of QVA149 on lung volumes and exercise tolerance in COPD patients: the BRIGHT study. Respir Med. 2014;108:584-592.

23. Wedzicha JA, Decramer M, Ficker JH, et al. Analysis of chronic obstructive pulmonary disease exacerbations with the dual bronchodilator QVA149 compared with glycopyrronium and tiotropium (SPARK): a randomised, double-blind, parallel-group study. Lancet Respir Med. 2013;1:199-209.

24. Bateman ED, Ferguson GT, Barnes N, et al. Dual bronchodilation with QVA149 versus single bronchodilator therapy: the SHINE study. Eur Respir J. 2013;42:1484-1494.
25. Mahler DA, Decramer M, D'Urzo A, et al. Dual bronchodilation with QVA149 reduces patient-reported dyspnoea in COPD: the BLAZE study. Eur Respir J. 2014;43:1599-1609.

26. ClinicalTrials.gov. Long term safety and tolerability of QVA149 versus tiotropium in Japanese patients with chronic obstructive pulmonary disease (COPD) (ARISE). Available from: http://www.clinicaltrials.gov/ ct $2 /$ show/NCT01285492?term=\%28ARISE\%29\&rank=4. Accessed October 20, 2014.

27. ClinicalTrials.gov. Comparison of long-term safety of the combination product QVA149A against placebo and standard of care treatment in chronic obstructive pulmonary disease patients with moderate to severe airflow limitation (RADIATE). Available from: www.clinicaltrials.gov/ct2/ show/NCT01610037?term=GLISTEN\&rank=1. Accessed October 20, 2014.

28. Vogelmeier CF, Bateman ED, Pallante J, et al. Efficacy and safety of once-daily QVA149 compared with twice-daily salmeterol-fluticasone in patients with chronic obstructive pulmonary disease (ILLUMINATE): a randomised, double-blind, parallel group study. Lancet Respir Med. 2013;1:51-60.

29. Zhong N, Wang X, Zhou N, et al. Efficacy and safety of once-daily QVA149 compared with twice-daily salmeterol/fluticasone combination (SFC) in patients with COPD: the LANTERN study. In: European Respiratory Society; September 8, 2014. Abstract 700090; Session 281.

30. ClinicalTrial.gov. A 52-week treatment, multi-center, randomized, double-blind, double dummy, parallel-group, active controlled study to compare the effect of QVA149 (indacaterol maleate/glycopyrronium bromide) with salmeterol/futicasone on the rate of exacerbations in subjects with moderate to very severe COPD (FLAME). Available at: http://clinicaltrials.gov/ct2/show/NCT01782326?term=COPD+novart is $+52 \&$ rank $=2$. Accessed October 20, 2014.

31. Dahl R, Jadayel D, Alagappan VK, Chen H, Banerji D. Efficacy and safety of QVA149 compared to the concurrent administration of its monocomponents indacaterol and glycopyrronium: the BEACON study. Int J Chron Obstruct Pulmon Dis. 2013;8:501-508.

32. Korn S, Gebner C, Schurmann W, et al. Once-daily QVA149 improves dyspnea, quality of life and reduces the rate of exacerbations compared to tiotropium plus formoterol in COPD patients: the QUANTIFY study. May 21, 2014. ATS abstract \# 50965(Publication number A5982); Thematic Poster Session D44.

33. Deliberation Result Report. Japan: Evaluation and Licensing Division, Pharmaceutical and Food Safety Bureau, Ministry of Health, Labour and Welfare; 2013. Available from: http:/www.info.pmda.go.jp/ shinyaku/P201300135/300242000_22500AMX01815_A100_5.pdf\#s earch= $\%$ E5 $\% 8 \mathrm{C} \% \mathrm{BB} \% \mathrm{E} 8 \% 96 \% \mathrm{AC} \% \mathrm{E} 9 \% \mathrm{~A} 3 \% 9 \mathrm{~F} \% \mathrm{E} 5 \% 93 \% 81 \% \mathrm{E}$ $5 \%$ B $1 \% 80 \%$ E5\%AF $\%$ A9\%E6\%9F\%BB $\%$ E7\%AE $\%$ A $1 \%$ E7\%90\%8 $6 \%$ E $8 \%$ AA $\%$ B2+\%E3\%82\%A6\%E3\%83\%AB $\%$ E3\%83\%86\%E3\%8 $2 \%$ A3\%E3\%83\%96\%E3\%83\%AD. Japanese. Accessed October 20, 2014.

34. Tashkin DP, Celli B, Senn S, et al; UPLIFT Study Investigators. A 4-year trial of tiotropium in chronic obstructive pulmonary disease. N Engl J Med. 2008;359:1543-1554.

35. Geßner C, Schurmann W, Forster K, et al. Once-daily QVA149 demonstrates superior improvements in lung function compared to tiotropium plus formoterol: the QUANTIFY study. May 21, 2014. ATS abstract \# 50961(Publication Number A5983); Thematic Poster Session D44.

36. Fourth Edition of the Japanese Respiratory Society COPD Guideline for Diagnosis and Treatment. Tokyo, Japan: The Japanese Respiratory Society; 2013. Japanese.

37. Spencer S, Calverley PM, Burge PS, Jones PW. Impact of preventing exacerbations on deterioration of health status in COPD. Eur Respir J. 2004;23:698-702.

38. Suzuki M, Makita H, Ito YM, Nagai K, Konno S, Nishimura M; Hokkaido COPD Cohort Study Investigators. Clinical features and determinants of COPD exacerbation in the Hokkaido COPD cohort study. Eur Respir J. 2014;43:1289-1297. 
39. Papaiwannou A, Zarogoulidis P, Porpodis K, et al. Asthma-chronic obstructive pulmonary disease overlap syndrome (ACOS): current literature review. J Thorac Dis. 2014;6:S146-S151.

40. Berrington de González A, Darby S. Risk of cancer from diagnostic X-rays: estimates for the UK and 14 other countries. Lancet. 2004;363: 345-351.

41. Ichinose $M$, Aizawa $H$, Ishizaka $A$, et al. [Chronic obstructive pulmonary disease (COPD) burden in Japan - confronting COPD Japan survey]. Nihon Kokyuki Gakkai Zasshi. 2007;45:927-935. Japanese.

42. Ishii T, Teramoto S, Miyashita A, et al. [Chronic obstructive pulmonary disease (COPD) in the elderly: analysis from questionnaire about attitudes to the COPD guideline of the Japanese Respiratory Society and actual therapy for COPD used by physicians]. Nihon Kokyuki Gakkai Zasshi. 2002;40:113-122. Japanese

43. Suissa S, Barnes PJ. Inhaled corticosteroids in COPD: the case against. Eur Respir J. 2009;34:13-16.

44. Calverley PM, Anderson JA, Celli B, et al; TORCH investigators. Salmeterol and fluticasone propionate and survival in chronic obstructive pulmonary disease. $N$ Engl J Med. 2007;356:775-789.

45. Aaron SD, Vandemheen KL, Fergusson D, et al. Tiotropium in combination with placebo, salmeterol, or fluticasone-salmeterol for treatment of chronic obstructive pulmonary disease: a randomized trial. Ann Intern Med. 2007; 146:545-555.
46. Wedzicha JA, Calverley PM, Seemungal TA, Hagan G, Ansari Z, Stockley RA; INSPIRE Investigators. The prevention of chronic obstructive pulmonary disease exacerbations by salmeterol/fluticasone propionate or tiotropium bromide. Am J Respir Crit Care Med. 2008; 177:19-26.

47. Suissa S, Ernst P, Vandemheen KL, Aaron SD. Methodological issues in therapeutic trials of COPD. Eur Respir J. 2008;31:927-933.

48. Shibuya K, Hashimoto H, Ikegami N, et al. Future of Japan's system of good health at low cost with equity: beyond universal coverage. Lancet. 2011;378:1265-1273.

49. Bean JR. National healthcare spending in the U.S. and Japan: national economic policy and implications for neurosurgery. Neurol Med Chir (Tokyo). 2005;45:18-24.

50. Miyata H, Motomura N, Kondo J, Takamoto S, Hasegawa T. Improving the quality of healthcare in Japan: a systematic review of procedural volume and outcome literature. Biosci Trends. 2007;1:81-89.

51. Yokokura Y. Efforts of the Japan medical association to support physicians to provide quality healthcare. Japan Med Assoc J. 2012;55: 205-207.
International Journal of COPD

\section{Publish your work in this journal}

The International Journal of COPD is an international, peer-reviewed journal of therapeutics and pharmacology focusing on concise rapid reporting of clinical studies and reviews in COPD. Special focus is given to the pathophysiological processes underlying the disease, intervention programs, patient focused education, and self management protocols.

\section{Dovepress}

This journal is indexed on PubMed Central, MedLine and CAS. The manuscript management system is completely online and includes a very quick and fair peer-review system, which is all easy to use. Visit $\mathrm{http}: / /$ www.dovepress.com/testimonials.php to read real quotes from published authors. 